Article

\title{
Community-Based Tourism as a Factor in Socio-Ecological Resilience. Economic Diversification and Community Participation in Floreana (Galapagos)
}

\author{
Esteban Ruiz-Ballesteros * $*$ and Alberto del Campo Tejedor(D) \\ Department of Social Anthropology, Psychology and Public Health, Universidad Pablo de Olavide, \\ 41013 Sevilla, Spain; acamtej@upo.es \\ * Correspondence: eruibal@upo.es
}

Received: 8 May 2020; Accepted: 7 June 2020; Published: 9 June 2020

check for updates

\begin{abstract}
In order to understand the effect of community-based tourism (CBT) on sustainability, bespoke instruments are required. This paper advocates the application of resilience thinking as a theoretical-methodological resource suited to this purpose. The methodological perspective proposed here focuses on two core elements in the functioning of any socio-ecosystem in which CBT is developed: (1) diversification of productive activities; and (2) collective participation in tourism. To reflect on this proposal empirically, an ethnographic case study was conducted on the island of Floreana (Galapagos). The analysis shows that resilience thinking is an appropriate strategy to study the effect and significance of CBT with regard to the general resilience of the socio-ecosystem and, therefore, the sustainability of its desired configuration. The analytical perspective proposed here allows us to understand: (1) how CBT functions in a specific case; (2) its contribution to the resilience of the socio-ecosystem; and (3) the consistency of that resilience by virtue of the functioning model of CBT. This analytical model furthers the study of CBT as a strategy for sustainability.
\end{abstract}

Keywords: community-based tourism; socio-ecological resilience; economic diversification; community; Galapagos

\section{Introduction}

Community-based tourism (CBT) is a means of organising tourism, defined by a series of principles: (1) local ownership and control over tourism resources and infrastructures; (2) local participation in planning tourism business; (3) local control over the management of tourism businesses and their profits, which must be reinvested in the community; and (4) the complementary nature of tourism in relation to other economic activities, without exclusively pursuing the accumulation of capital [1-5]. This approach means that CBT is locally driven, empowering the community through the development of tourism. These principles are developed at different levels and intensities in each CBT experience, giving rise to major plasticity within CBT experiences, even in the same country [6]. However, international organisations, governments, NGOs and even indigenous organisations have gradually turned to CBT as a mode of alternative tourism that promotes sustainable local development in terms of the triple bottom line (economic, environmental, and social).

If CBT can potentially improve quality of life and environmental conservation, it will do so as a socio-economic activity that helps to shape a socio-ecosystem into the desirable configuration, thereby nourishing its socio-ecological resilience. Social-ecological resilience is the capacity of a socio-ecosystem to absorb disturbance and reorganize while undergoing change so as to still retain essentially the same function, structure, and feedbacks, and therefore, identity [7]. Rather than a static concept of sustainability (conservation), the notion of resilience offers a more dynamic vision, one that 
views change as inherent to any system and posits that such transformations must be dealt with so that the system may endure without losing its identity [7]. From this perspective, resilience becomes a fundamental analytical tool: CBT is a sustainable activity if it becomes a vector for the general resilience of the socio-ecosystem [8].

In the case of CBT, not only does tourism play a prominent role in the definition of the socio-ecosystem and, therefore, in its sustainability, but also, in many of these situations, CBT has been developed as a conscious strategy to pursue socio-environmental sustainability. Resilience has a clear practical dimension [9] linked to the way in which humans behave within their environment and establish socio-economic relations. The development of CBT is a vector of resilience insofar as it significantly influences the way in which the socio-ecosystem is configured and functions in its physical, biological, sociological, economic, political and cultural dimensions. CBT moulds local attitudes and behaviours that then transcend tourism and introduce patterns of behaviour that affect all other social and productive activities. The sustainability or non-sustainability of CBT can be better understood using the analytical framework of socio-ecological resilience [10].

The aim of this paper is to gain a better understanding of how CBT can enhance the resilience of a socio-ecological system and to further develop the analytical strategies available to study it. The starting premise for this research is that if CBT increases resilience it will also foster sustainable development and reduce the social and environmental vulnerability of a socio-ecosystem. To explore this relationship between CBT and resilience, a case study conducted on the island of Floreana, in the Galapagos archipelago, shall be examined, in which CBT offers a means of achieving sustainable development in a highly sensitive environmental setting, and one that requires its inhabitants to consolidate an economy in harmony with the demands of conservation.

To develop this line of inquiry, we shall first define the fundamental factors of resilience that must be considered from the perspective of CBT. We will then present the case study and the research methodology applied, before describing how CBT is a vector for resilience in Floreana. Finally, we shall endeavour to draw conclusions that go beyond this specific case study and further our understanding of how CBT affects socio-environmental sustainability.

\section{Factors of Resilience and Community-Based Tourism}

Socio-ecological resilience is a fundamentally dynamic concept that helps us to understand how a socio-ecosystem maintains a certain configuration in spite of the inherent change to which it is subjected [7]. Multiple factors affect these kinds of processes that entail 'permanence in spite of change'.

On a practical level, a socio-ecosystem is a defined territory in which physical, biological, social and cultural elements interact. To apply a necessarily complex analytical approach that focuses on its resilience, hierarchies must be established between these heterogeneous components. To do this, we must first acknowledge that humans clearly play a prominent role in the functioning of any socio-ecosystem and also in its resilience. Humans are the elements of a socio-ecosystem that most intensely condition its physical, biological, social and cultural configuration [11-19]. Therefore, they also play the leading role in determining its resilience. This is not only because the desired configuration is a subjective and political question [7], but also because the materialisation of any specific configuration is shaped by human behaviour and practices [9].

Based on this premise, in order to understand how a socio-ecosystem functions and evaluate its resilience, it seems more appropriate to focus on the relationships established between the humans that inhabit it and the biophysical environment at all levels. Within this framework of interactions, the socio-ecosystem takes on a certain configuration-desirable or undesirable-in which the form taken by this human/environment interaction (which obviously includes interactions between humans themselves) is seen to be a factor of resilience or not, as the case may be. In the specific situation analysed here, the aim is to examine the effect of a specific activity-CBT-on the general resilience of the socio-ecosystem. Therefore, we must be able to generate a vision of the socio-ecosystem and its resilience that focuses on CBT as an activity. 
The way in which humans and environment interrelate is chiefly encapsulated in the form that human activity takes within that environment. Practices embody materiality and human influence in the space, as well as human ideas and conceptions about their environment. The exploration of this issue must seek to understand how the human community proceeds and functions within its environment, studying attitudes and practices, rather than examining just the structural configuration of the socio-ecosystem $[9,10]$.

The general resilience of a socio-ecosystem is conditioned chiefly by three factors: (1) the diversity of productive activities developed and how they are organised and structured [20,21], since these are the main causes of biophysical effects and reflect the socio-economic and political dimensions (this diversity enables the socio-ecosystem to adapt efficiently to transformations that affect any of those activities, since it does not rely solely on any of them); (2) human learning capacity, enabling the development if necessary of new tactics and strategies [22] to interact with the environment [23]; and (3) the collective participation levels of the human community that makes up that socio-ecosystem and their place attachment [16,24-26], since this allows for cohesion and coherence in human action with regard to the environment. Through these factors, the analysis of general resilience can be made operational. However, our interest in this case is more specific: we are seeking to clarify the effect of CBT on that general resilience in order to evaluate its possible transcendence in terms of the sustainability of the socio-ecosystem. By specifying our precise research aim, we will focus analytically on two particular factors, which will help us to understand the effect of CBT on resilience.

(a) Firstly, we consider the diversification of activities within the socio-ecosystem and the role CBT plays in that diversification. It is important to understand all the activities that link humans and the environment, the importance of each activity and the dimension of CBT at different levels (economic, environmental, political, discursive) and scales (individual, family, community). It is crucial to ascertain whether CBT achieves its goal: to ensure that tourism does not monopolise the community's time and energy to the detriment of other activities. A socio-ecosystem in which a single activity - whatever that might be - is established almost exclusively, or becomes excessively dominant, is not resilient, since any alterations in the conditions that enable that activity would then endanger the whole configuration of the socio-ecosystem, which is incapable of sustaining itself. The socio-ecosystem would be clearly vulnerable. Therefore, it is crucial to understand the extent to which productive activities are complementary and to determine the role played by CBT in their maintenance. All of this is in harmony with the promotion of biodiversity and socio-cultural diversity, which facilitates the plurality of possible responses to unexpected bio-physical and socio-economic transformations and the need for alternatives to ensure subsistence [7]. One of the fundamental consequences of the diversification of activities is that it allows a community to overcome its potential vulnerability in terms of food sovereignty, seeking to ensure that primary productive activities are not abandoned or geared exclusively towards the market in the form of industrial monoculture.

(b) Secondly, it is particularly important to study the effective involvement of the local population in tourism: the extent to which and how the local population participates in CBT, its forms of governance, and above all, how everything related to CBT is structured and organised at an individual/family/community level [27]. In short, the aim is to see how CBT becomes a collective practice within the socio-ecosystem, otherwise we will be unable to calibrate its specific weighting and, therefore, explain how and the extent to which it contributes to the resilience of the socio-ecosystem (for example, through the further diversification of activities). From this analytical perspective, it is possible to identify whether CBT enhances learning capacity and innovation, encourages collective participation, and consolidates feelings of place attachment among the local population.

The two factors selected to apply our chosen analytical approach undoubtedly have bio-physical and socio-cultural implications, and there is a clearly recursive relationship between them. By analysing 
the effect of CBT on resilience, its role in the diversification of activities, and local involvement in tourism, we see that these two phenomena are by turns cause and consequence of the other. As observed in other cases $[10,28]$, tourism is more than an economic activity, since it sustains a certain way of being within a territory and can even impose specific ways of conceptualising and managing other more conventional resources. However, tourism cannot be set up as a single logic that articulates the relationship between humans and environment; if it were, instead of enhancing resilience, it would increase the vulnerability of the socio-ecosystem.

\section{Case Study and Methods}

The Galapagos Islands are located in the Pacific Ocean. A province of Ecuador, the estimated population was in excess of 30,000 inhabitants in 2019 (25,244 according to the 2015 census), and they received 271,000 tourists in 2019 [29]. In 1959, the Galapagos National Park was created with a view to protecting the island's unique and extremely sensitive ecosystem, and it was declared as World Heritage site in 1978. The Galapagos Islands are one of the world's greatest sanctuaries for biological research and nature tourism.

Floreana is the smallest of the inhabited islands, covering an area of $173 \mathrm{~km}^{2}$ with a population of 147 inhabitants. Like the rest of the archipelago, Floreana has only had a stable human population from the 19th Century onwards, but it has experienced periods of total depopulation since then [30,31], reaching its current configuration as a result of new resettlement from the 1930s onwards. Human occupation, therefore, barely stretches back more than a few generations and it is very heterogeneous, lacking in an island cultural tradition. The way in which humans have occupied the island has strongly shaped social relations, dominated originally by the model of pioneer family and individualism, more conducive to competition than cooperation. However, with the arrival, from the 1970s onwards, of a second wave of migration, made up of families from the Ecuadorian province of Loja, there has been a quantitative increase in the population and in the development of certain practices based on mutual support and reciprocity (lending of land, barter, festive celebrations ... ).

There is a significant socio-political gap between the descendants of the settlers from the 30s-40s and the new families from Loja, representing two worlds on one small island. The cultural difference between the pioneering settlers and the migrants from Loja is marked, a situation that is further exacerbated by the fact that these latter immigrants have tended to occupy a subaltern position. In addition to this circumstance, Floreana has been shaped by its acute isolation from the outside world until well into the 21st century, cut off from the tendencies that affected the rest of the archipelago (first boom in fishing, and then tourism).

In spite of the size of the island and its scant number of inhabitants, contrary to expectation a 'community' in the more classic anthropological sense has not developed here. In fact, there is clear internal heterogeneity, and significant inequalities have been generated mainly in relation to land ownership. $98 \%$ of the island is publicly owned in accordance with a regime of environmental conservation. The remaining $2 \%$ is distributed between the urban nucleus of Puerto Velasco Ibarra on the coast $\left(0.39 \mathrm{~km}^{2}\right)$ and another area of farmland on the upper part of the island $\left(2.71 \mathrm{~km}^{2}\right)$. This private land is owned fundamentally by the first settlers, who claimed it before the park could prevent the occupation of new areas of land.

Owing to their secular isolation, the inhabitants of Floreana have relied on their own capacity for subsistence in order to survive; hence the importance of having farmland and access to water (very scarce on the island). The natural surroundings have been profoundly altered by anthropic activities: firstly the introduction of animals (cows, donkeys, goats, dogs, cats, rats) and foreign plant species (orange trees, avocado trees, blackberry bushes), and the depletion of native species (tortoises); and subsequently by the development of agriculture on the upper part of the island. In a fragile environment such as Floreana's, all these activities have helped to generate hybrid ecosystems, markedly different from those that pre-existed human presence, but which nonetheless retain much of 
their peculiarity in terms of species and configurations. In fact, small islands are particularly favourable to the development of changing and hybrid ecosystems [32].

In spite of everything, until recently Floreana remained relatively unaffected by recent impacts insofar as the state and the market had a very limited presence in island life, which was instead somewhat autarkic. However, this tendency altered in the first decade of the 21st century [30]. The state began to have a stronger presence through conservation policies and public intervention (employees in the National Park, public administration and parish council budgets). Furthermore, the market infiltrated the island when, in 2006, tourist routes were set up from Puerto Ayora, the economic capital of the archipelago. Before that time, cruise liners visited the northern part of Floreana but did not come into any contact with the local population. From 2006 onwards, visitors began to arrive from Santa Cruz and stay for around five hours for a daytime tour of the island that visited the upper part-including Asilo de la Paz, the first stable human settlement-included lunch in one of the restaurants in the town and, after a short stroll along the beach, return to Santa Cruz. This type of visit is referred to ironically by the locals as "whistle-stop tourism" [turismo relámpago]. In 2014, around 20,000 tourists visited Floreana. This influx favoured the development of tourism on the island: transport (land and sea), restaurants, retail, and complementary activities. The flows of tourists were managed by operators at Puerto Ayora; the residents of Floreana only billed for services provided and did not control the business. The development of tourism consolidated the connectivity of the island, initiated an unprecedented monetisation of its economy, and increased living standards and levels of consumption among the inhabitants.

As of 2010, Floreana became fully inserted within the state and the market, but it did so from a situation marked by internal social inequality and heterogeneity, without a community structure and organisation in place that would position it appropriately to navigate between the state and the market. Between 2009 and 2019 (the period in which the fieldwork for this research was conducted), pressure from speculation and construction on the island of Floreana was extremely intense, and over twenty local tourism businesses were developed (family-run lodgings, hotel, restaurants). Furthermore, external investors were keen to seize investment opportunities on the last island in the archipelago to develop tourism. Ángel, a civil servant and restaurant owner, put it eloquently: "tourism caught up with us".

As seen in many other places, and on the Galapagos Islands themselves [30], market penetration in self-supply economies, and especially tourism, devastates other sectors, particularly food sovereignty. This is the current scenario in Floreana, and its inhabitants are well aware of what has happened on neighbouring islands. Tourism as an activity becomes a source for reflection, a catalyst, spurring them to analyse a way of life that feels threatened. On the one hand, there is growing awareness of the limited-or practical absence of-control held by local society over the flows and types of tourism. On the other hand, there is increasingly evident danger that farming activities will be abandoned in favour of monetisation and "more advantageous" forms of work offered by tourism. In short, there is a clear understanding of the advantages of opening the island up to the outside world, but at the same time, there is an awareness of the inherent vulnerability that threatens the autonomy of its inhabitants and their way of life. In response to this concern, a model of community-based tourism was developed, which would allow the island's inhabitants to position themselves in relation to the market and the state itself.

Concern is not only felt by the inhabitants of Floreana. The environmental authorities (National Park) are also increasingly worried about the impact of tourism on the environment of the last island that had been free from tourism. The limiting factors of water and demographic control are crucial to ensure that an alteration to the main environmental drivers will not endanger its current configuration, seriously affecting the island's ecosystems and the species that inhabit it.

Therefore, the implementation of CBT in Floreana would have been impossible without the convergence of internal and external stakeholders and interests; in short: without the development 
of a multilevel adaptive co-management system involving local community, tourist industry, NGOs, and the Ecuadorian government (ministries of tourism and environment), as discussed elsewhere [33].

From 2009 onwards, a process of collective reflection was launched, led by the parish council, which implicitly determines a desired configuration for the socio-ecosystem based on the local control of tourism. At an assembly meeting, Max Freire, the council president, justified why the people of Floreana should come together to manage tourism: "we want tourism to come and adapt to the island, not the other way around." This statement of intent explicitly sets out the determination to effect a crucial change in tourist activity: the organisation of tourism should swing towards supply and not take external demand as the sole reference. In contrast to 'whistle-stop tourism', the aim is to modulate tourist activity-controlling its flows and forms-to ensure its development does not erode everyday life. At that same assembly meeting, the islanders claimed that their lifestyles and their different "authentic island" values were being threatened by tourism: tranquility, safety, and togetherness. They also sought protection from external investments and businesses, and at the same time requested greater local protagonism in the development of tourism: in fact, they sought exclusivity in the form of community-based tourism. Their proposal was based on a more complete development of the local tourism offer, so that they could increase their incomes and improve life on the island. The means of doing this was the collective management of tourism. Individual operators could not take on the threat of external investment alone, or hold a strong position with regard to tourism and environmental authorities, or indeed present a consistent alternative.

Furthermore, local society accepted the need to modulate the flow of tourism so it would not continue to have an irreversible impact on the environment. To achieve this, the food sovereignty of the island was also essential, meaning it was crucial to maintain and develop farming and fishing activities. In short, the aim would be to reduce the number of visitors and increase overnight stays on the island, thereby increasing revenues generated, whilst at the same time diminishing the ecological pressure of tourists on the island (water consumption, waste generated, mobility, the need to bring in external products), but also to influence quality of life for the inhabitants of the island: reducing the effects of traffic (noise, dust), lowering levels of stress caused by having to deal simultaneously with so many visitors, and enabling them to dedicate their time to other more pleasurable activities (growing fruit and vegetables, harvesting).

In August of 2019, after a few years' of trying out this new tourist product, one of the members of the parish council made the following statement at a meeting:

There has been a substantial reduction in the type of tourism that ferried tourists in for the day so they could visit the upper part of the island, go snorkeling, have lunch and then leave. That was torture, we couldn't cope ... such a commotion, cars going up and down constantly .... Things are better now, tourism is calmer, tourists stay overnight, and there has been economic improvement. The situation between service providers is also fairer.

All the members of the parish council, the majority of whom also participate in tourism, agreed. But does this new mode of community-based tourism truly make the island more sustainable? How does it contribute to the resilience of the island's socio-ecosystem? These questions will guide a more general reflection on the effect of CBT on socio-ecological resilience.

The experience of CBT on Floreana has a very peculiar structure. CBT can come in a variety of different forms, but the model used in Floreana could be one of the least 'community-based' approaches possible. Some collective tourist products have been created, but the basis for tourism is made up of family-run businesses. There are no explicitly collective enterprises, with the exception of the local tour operator itself. Therefore, CBT is circumscribed to the coordination and allocation of demand to family-run transport, accommodation, restaurants, and other tourist businesses. It also manages a communal fund generated by $10 \%$ of tourist revenues, which is controlled by the community organisation. 
An exploratory and longitudinal ethnographic case study was conducted on the island of Floreana between 2009 and 2019, extensively monitoring the process examined here, with 11 months of intensive fieldwork carried out through different campaigns (2010, 2011, 2012, 2013, 2014 2015, 2019). Bearing in mind the island's tiny population, and our successful integration into local society, the fundamental technique used was direct and participatory observation of local life, focusing on the effects and developments of tourism.

More specifically, different socio-demographic and economic analyses were conducted utilising ad hoc interviews and data from secondary sources. Community size made the use of sampling techniques unnecessary, thus research work (observation, interviews) has been carried out with all domestic groups and adults in the community throughout the different periods of fieldwork. These processes were repeated at different times during the fieldwork campaign $(2010,2013,2019)$. Furthermore, a complete institutional study was carried out (on organisations and networks) at a local level, which involved attending meetings and collective gatherings. In-depth interviews with adult members of all households (35), at different points during the research, allowed us to analyse the attitudes of the inhabitants with regard to quality of life, tourism, development, and interactions with the environment.

Bearing in mind the duration of the research conducted, we have been able to implement a longitudinal perspective that is unusual in this type of approach, but which is essential to the subject we are studying here.

Analysis of obtained data was based on triangulation of the different techniques used and an application of theoretical saturation, as derived from grounded theory [34,35]. For each of the research topics (quality of life, tourism, development, interactions with the environment, etc.), codifications were developed to classify the different types of data. The processes studied were then analysed and described based on these codes.

\section{Floreana: Community-Based Tourism as a Factor in Resilience}

From 2006 onwards, the development of tourism on the island of Floreana was shaped by an influx of visitors controlled by external operators that contracted local drivers and restaurants to provide the services required for that 'whistle-stop tourism' described previously. This model not only saturated the island with up to 10 boats a day during peak season and more than 20,000 visitors a year, but it also barely left $20 \%$ of its revenues on the island. Since 2017, once this model of tourism entered a profound crisis - resulting from a pricing war between operators-and underwent major reorganisation, another model of tourism, promoted locally, has been implemented, based on longer stays on the island (three/six days), driving up revenues for restaurants and accommodation, and facilitating the development of other services (guides, activities). This has been made possible by the creation of a collective organisation that groups together local tourism enterprises, which prior to that point had been operating separately, trying to take on external operators individually. This approach to CBT seeks to increase local control over and local benefits from tourism, whilst at the same time safeguarding quality of life on the island and halting the negative impact of tourism on its ecosystems.

In 2010, we attended a general assembly meeting where it was decided to promote a collective organisation to manage tourism on the island. However, there were various ups and down, as well as administrative problems, and the Floreana Community Centre (Centro Comunitario Floreana-CECFLOR) was not legally recognised until 2014, integrating 71 local members, who were linked with tourism or not as the case may be, and who represented practically all the households on the island. In 2015, the National Park of the Galapagos signed an agreement with CECFLOR to co-manage tourism in the north part of Floreana, an agreement that was expanded and further quantified in 2018. This agreement entails de facto the creation of an exclusive tourist product for the inhabitants of Floreana, organised as a community, which is unprecedented on the Galapagos Islands. In 2016, Floreana Post Office Tours Cia. Ltda. began operating, a tour operator that is $99 \%$-owned by CECFLOR and which now organises CBT on the island. 
How does this experience favour greater social, economic and ecological sustainability for the socio-ecosystem? Analysis of two specific factors from the perspective of socio-ecological resilience-diversification of activities and the effective involvement of the local population in community-based tourism—should clarify our understanding.

\subsection{Community-Based Tourism and the Diversification of Activities}

At the end of the 20th Century, Floreana's economy was still largely circumscribed by self-supply. The expansion of public employment, followed by the development of tourism radically transformed the functioning of the socio-ecosystem, diversifying its activities. Agricultural production was complemented by imports of food products thanks to increased connectivity, and environmental conservation became the dominant logic on the island. However, the growing influx of tourists from 2006 onwards forced an exponential increase in the consumption of external products and an unprecedented use of local resources, in addition to a substantial change in the island's ways of life. One might expect the increase in tourism to lead to the abandonment of primary production and, therefore, to the reduction of economic diversification, with the risks this brings with regard to resilience (for example, food sovereignty). However, the data about the activities of households and their recent evolution refute this tendency (see Table 1).

Table 1. Households engaged in productive activities 2011-2019.

\begin{tabular}{ccccccc}
\hline & $\mathbf{2 0 1 1}$ & & $\mathbf{2 0 1 5}$ & & $\mathbf{2 0 1 9}$ \\
\hline Population & 159 & & 155 & & 147 & \\
Households & 31 & $100 \%$ & 35 & $100 \%$ & 34 & $100 \%$ \\
Public administration \& Services & 19 & $61 \%$ & 23 & $66 \%$ & 28 & $82 \%$ \\
Tourism & 15 & $48 \%$ & 22 & $63 \%$ & 30 & $88 \%$ \\
Crop Farming & 20 & $64 \%$ & 21 & $60 \%$ & 23 & $68 \%$ \\
Livestock Farming & 18 & $58 \%$ & 19 & $54 \%$ & 19 & $56 \%$ \\
Construction & 11 & $35 \%$ & 4 & $11 \%$ & 11 & $32 \%$ \\
Visitors & 23500 & & & & $9000^{*}$ & \\
\hline
\end{tabular}

Source: fieldwork and [36]. *2018

This table shows the number of households that participate in each of the different productive activities on the island and the changes observed over the past nine years. Whereas tourism has a growing presence in the activities of households (in nine years, households participating in this activity have increased from $48 \%$ to $88 \%$ ), public employment has also grown (administration and services), and food production activities have been maintained. Tourism gained a strong foothold but did not become the dominant activity. The salaries available through public employment are highly valued, as are the savings and quality offered by producing local food products (agriculture and livestock farming) for self-consumption, exchange, and small local sales (including some for tourist businesses). In fact, the most appropriate way to describe the new regime of productive activities on the island of Floreana would be precisely to point towards a system of tourism/public employment/farming production. More than $50 \%$ of the local households participate in this model of multi-activity.

CBT does not imply relying solely on tourism. The large majority of households on the island $(64 \%)$ participate in tourism, but it is not the sole source of income for any of them. Tourism is integrated into the local economy without jeopardising its plural development. Let us not forget that the explicit objectives of the CBT proposal were to close tourism off to external investment, to constrain and limit tourist numbers, and to enhance the viability of other productive sectors:

[tourism] ... is a driving force that we need, which favours fishing, farming, and local crafts. Everything must revolve around it. But tourism should not change our lives so that we end up buying everything in Santa Cruz [economic capital of the archipelago]. We must clearly understand that not all of us will be in tourism; fishing and agriculture are also necessary. We need to promote these sectors as well as tourism (A., 2012) 
These aspirations and the creation of an organisation that represents all interests on the island through its families (CECFLOR) are not limited exclusively to tourism, although this activity is the most striking on account of its progression in recent years. Specifically, in parallel to this process, the "Verde Floreana" association has also been set up, grouping together local agricultural farmers (many of whom are also linked to the development of tourism). This organisation has encouraged collective sowing, acquired common infrastructure, and provides a range of different services for farming.

Therefore, community-based tourism has not hampered the development of other economic activities. It has encouraged them by virtue of the founding principles of CBT and CECFLOR, also fostering the demand for farming products. These effects are clear throughout the socio-ecosystem as a whole (as seen in the general figures), but they become even more evident and eloquent when we look at individual households. In terms of the functioning and evolution of these families, it becomes clear how this productive diversification, which enhances the resilience of the socio-ecosystem, takes shape at a micro level. Let us examine a few cases.

(a) A. and R. live with one of their daughters; the other two are on the island of Santa Cruz, where they are studying. A is a public employee, and $\mathrm{R}$ works in one of the two local hotels. They have decided to open up a restaurant and they have a small landholding on which they grow food and keep animals. For A. "it is important if you have land, it helps you to produce food, not to sell, there's no market here, and it's hard to take it off the island, although it will be very important for our restaurant: my plot of land helps me with the restaurant." In fact, their family buys any hardly vegetables or meat since they produce it themselves. In spite of having two salaries (public sector and tourism), the maintenance of farming activity is still a fundamental pillar of their household economy.

(b) M. worked for several years in local government and V. was an employee at one of the island's restaurants. They live together with her daughter. Over the past few years, they have entered tourism fully: they opened a restaurant managed by V., they set up a small tour operator run by M., and they built cabins to provide accommodation, where they also live. V. and M. have also played a prominent role in the creation and management of CECFLOR and Floreana Post Office Tour from the outset. They recently bought two hectares of land to grow food. This land-which they work along with one employee-provides food for their home and their restaurant. They enjoy their land and are constantly working to improve it.

(c) E. is a local entrepreneur, chiefly in the construction sector but also in tourism. He lives with his wife, D., and their two children, in a house surrounded by cabins for tourist accommodation and their employees. He has developed much of the new construction built on the island since 2009. It might seem that with construction and tourism, they would have had sufficient activity, but a few years ago they purchased two hectares of land on the upper part of the island to grow food, and they aim to buy more land to grow agricultural products for exportation.

(d) P. and A. are public employees and they live with their three children. P belongs to one of the oldest families on the island and owns land on the upper part of the island. Although they live very comfortably as public employees, they are investing in their plot of land to improve production (using a tractor, setting up irrigation, improving the chicken coops) and making it suitable to live there when the vehicle they have bought arrives. They are looking for a calmer pace of life on the upper part of the island, far from the commotion of the port and tourism. For them, working on their land is complementary to their public sector jobs: it provides them with recreation, supports their household economy, and offers them a way to escape from the daily grind of their jobs. They are not involved with tourism in any way and do not intend to become so.

(e) I. is one of the most important agricultural farmers on the island. He was never against tourism; in fact, one of his children studies tourism at university and cannot wait to return to work in this sector. But for I., Floreana is synonymous with plants and pets. He lives with his wife and two children, one of whom is a public employee. He spends every day on the upper part of the 
island where he has two large plots of land, which he uses to produce what he needs for his everyday life, as he has done for the past 40 years when he first arrived on the island. Now he sells or gives away much of his produce to neighbouring restaurant owners.

All the people mentioned above are members of CECFLOR. Participating directly or indirectly in CBT does not imply closing oneself off to anything else; quite the contrary. The complementary development of agricultural farming, livestock farming and tourism is evidence of the way CBT has developed on the island of Floreana. The cases illustrated here-representative of the local community as a whole-show that earnings from government employment and/or tourism are often used to develop farming activity with various effects: increasing the food sovereignty of Floreana; fostering an affective bond between the local population and the upper part of the island; keeping the agricultural space active, with no danger of abandonment; and encouraging more relaxing activities, linked to the land, plants and animals, which are seen as buffers against stress and productivity. This is all clearly identified within the organisation of households and even in the individual pluri-activity of some of its members. From the perspective of CBT, tourism is not an end in itself, but rather a means of maintaining and favouring other activities, with the inestimable help of public employment.

All of this further accentuates the need for reflection on tourism, the type of model used, and the thresholds envisioned. The limitation of flows and revenues, the reduction in visitor numbers (which have been more than halved) and the type of product offered become a decision to be made locally, and this process is not without conflict, as we shall see below.

What is clear at this point is that CBT promotes and favours other activities, particularly farming, thereby enhancing the resilience of the socio-ecosystem for different reasons: (1) it helps to bring down visitor numbers, thereby reducing their environmental impact; (2) by favouring local farming production, it helps to reduce the influx of external farming products (a factor for conservation of endemic flora and fauna); (3) it has a direct effect on the island's food sovereignty, reducing its vulnerability to fluctuations in the tourist market, as shown in the crisis and the island's total isolation from the COVID-19 pandemic; and (4) it helps to restore a lifestyle, linked to farming, with a slower pace of life, which had been jeopardised by the development of 'whistle-stop tourism' that brought visitors to this small island in their droves.

\subsection{The Community in Tourism}

If CBT favours the resilience of the socio-ecosystem by modulating the flow of tourism and contributing to the diversification of activities on the island, it is crucial to ensure that the participation of the local population in tourism is effective and consistent, in order to guarantee these effects over time. Otherwise, CBT itself would be a vulnerable activity, unable therefore to sustain the resilience of the desired configuration of the socio-ecosystem and its sustainability.

To study the role of the community in the experience of CBT on Floreana, we will analyse a series of circumstances and processes with a view to clarifying the forms, meanings and dimensions of this collective participation in tourism: the involvement of the island's inhabitants in tourism, CBT governance, collective action around the planning/creation of the tourist product, and collective decision-making/conflict resolution in the implementation of CBT. Based on all of this, we can reach certain conclusions about the effect of CBT on socio-ecological resilience.

\subsubsection{Local Involvement in Community-Based Tourism}

CBT in Floreana integrates 8 of the 10 hotel establishments on the island (50\% of hotel places); all the restaurants on the island (five), transport vehicles (four) and sea taxis (two), in addition to all tourist service providers (snorkeling, kayaking, cycling, and guides). All these services are family-run enterprises led by 22 households, which also employ eight people from other families. Therefore, 30 households participate in CBT. This means that more than half the adult population participates directly in tourism. Tourism entrepreneurs (accommodation and restaurants) generally come from better-off families, most of whom hold public jobs and have land, which they use to supply food to 
their restaurants. Therefore, they reflect in their household economics the diversification of activities that characterises the socio-ecosystem as a whole. Employees, meanwhile, combine tourism with other activities. Tourism is not the sole activity of any business owner or employee.

Hotels and restaurants all receive the same revenues from CBT, since tourism flows managed by the community tour operator are shared out equally. Therefore, revenues from tourism reach, directly or indirectly, a very significant part of the local population, who also participate actively in tourism.

\subsubsection{Governance of Community-Based Tourism}

CECFLOR, through its tour operator, subcontracts group visits to the island to external operators. The demand for services (accommodation, food, miscellaneous services) is then distributed among the members of this association, applying a criterion of equity and rotation, regardless of the size of their businesses. The aim is to ensure they all have the same turnover at the end of each year, and this has been the case so far.

In theory, all tourist services should be managed through CECFLOR, but in practice, and bearing in mind the diverse starting position of its members (already operating prior to the constitution of CECFLOR), this is not the case. In fact, local tourist business owners have two streams of business: on the one hand, business from the community operator; and on the other, business from each entrepreneur's previous customers (approximately 50\% of total sector revenues). This allows them to cope with inequality in the size and potential of each business. Enterprises receive the same customers through CBT but they also retain their individual business shares. For more powerful enterprises, CBT is a complement to their turnover; for smaller businesses, it forms the basis of their incomes.

However, this way of combining collective demand and individual demand shapes a hybrid model of tourism, which is a source of conflict on account of the prices that can be charged for the same service if it is requested through the community tour operator or has been managed individually. The community operator retains $10 \%$ of the prices for the services it manages. Business owners, therefore, might be tempted to lower their prices by that much when offering services privately, thereby engaging in unfair competition with the community operator.

The revenues earned by CECFLOR are used to pay its administrative staff and to cover its running costs. The remainder is invested in the community, as decided by the members.

In the three years since it was set up, there has been some very harsh criticism levelled by members regarding the community management of tourism. They question the logic used when distributing customers, as well as the quality of the different services offered, since customers are distributed without taking into account of the different facilities and features of accommodation and restaurants. The prices are the same for all, and each business receives the same number of customers.

\subsubsection{Collective Action Around the Planning/Creation of the Tourist Product}

One of the main objectives of CBT in Floreana is to change the patterns of tourist consumption on the island. To do this, a new tourist product must be developed that encourages visitors to stay overnight on the island, thus overcoming the limitations and impacts of 'whistle-stop tourism'. Visitors must be given options that would justify spending several days on the island. Hence, a decision was made to provide road access to tourist places previously reserved exclusively for cruise liners, bases on the idea of the community's right to its island. The trail to Post Office Bay is a strategic element for CBT since it opens up access and provides an unprecedented product for the community. Of particular significance in this regard was the participation of the whole community, by means of Minka community labour, in the recovery and opening of the old trail that leads from the upper part of the island down to the bay. It was understood that this collective action in 2012 gave tangible meaning to the CBT experience, for two reasons: (1) the level of participation (practically all households took part in the work); and (2) the extreme harshness of this work (construction/recovery of the trail involved many days' work in unfavourable weather conditions, covering tricky terrain). Beyond the constitution of 
CECFLOR as a local community institution, it was the significant opening of this trail that represented a turning point, laying the foundations for community-based tourism in Floreana. This not only led to the creation of a tourist product, but also the local community was able to appropriate it since it was their own toil that had made it possible. Building a common tourist product, which became the pillar of CBT on the island, provided a solid foundation for this collective approach to tourism.

The leadership of the parish council was essential in this process. In fact, we can focus on another parallel collective: the signing of the agreement recognising co-management of tourism between the National Park and CECFLOR for the northern part of the island (where this trail leads). With bold political action-unprecedented on the archipelago and based on the capacity for local collective action - this new tourist product has been consolidated as a kind of tourism "common". De facto, this agreement allows a modest community tourism organisation to share the tourist product with the international lobby that controls tourism on the Galapagos Islands and which, up until that moment, had the exclusive right to access that area of Floreana.

\subsubsection{Collective Decision-Making and Conflict Resolution}

Participation, governance and collective action are shown especially when it comes to making decisions and resolving tensions and conflicts, which are very frequent in any collective activity, CBT being no exception. During our fieldwork in Floreana, various situations and circumstances arose that tested the collective capacity to decide or resolve. In 2018, a particularly illustrative process was observed around the type of tourist offer that should be promoted as CBT: negotiations with CECFLOR's main client to renew tourist packages and prices.

Some of the entrepreneurs argued for a major price increase in the cheaper more popular services in order to reduce visits whilst assuring the same earnings. The operator refused. Following this ultimatum, those who were less convinced by the strategy were willing to reconsider the demands made, but eventually negotiations broke down, and the client refused to continue working with CECFLOR's cheaper services. This placed CBT in a potentially critical situation.

This decision-making process laid bare the distances between the members of CECFLOR, and their different visions of how tourism should be. A major rift was created with very serious consequences, especially for smaller business owners who largely depend on demand from CECFLOR. At the same time, however, it strengthened the determination of others to achieve an exclusive retail type of tourism for the island as soon as possible.

The inability to resolve this conflict meant that it spread beyond the collective management of tourism and impregnated local politics in all its dimensions, generating social fracture on the island, the likes of which had not been seen for more than a decade. All levels of local politics and administration were affected. Strategic dissent within the area of tourism triggered a general schism within the community. The two halves into which local society split embarked on a frantic struggle to control the different areas of socio-politics (parish council, banking branch, local representatives of central government) and, of course, CECFLOR.

Up until that point, the development of CBT in Floreana had been the result of reigning consensus in all the strategic aspects of the island. Following this unresolved conflict, CBT became a trigger for local fragmentation that even affected the celebration of the island's most important festivities. But above all it highlights the difficulty in achieving collective agreements and underscores the structural differences between the members themselves, questioning the viability of CBT and, therefore, the durability of its socio-environmental effects.

As we have already seen, the involvement of inhabitants in tourism is strongly shaped, with regard to business owners, by families that enjoy a more comfortable socio-economic position on the island. Although collective action in strategic matters (post-office trail, agreement with the National Park) has been a resounding success, governance of CBT is weighed down by the problematic interlinking of collective demand with the individual demand of tourism businesses, that jeopardises the competitiveness of the strictly collective product. All these uncertainties erupted traumatically 
as soon as the first strategic decision made after CECFLOR had been operating for two years (renewal of the agreement with its biggest client) produced a schism between the members that spread to the whole of community life. Therefore, collective involvement and participation is not without its difficulties and challenges for the consistent development of CBT. In this case, it harks back to the social differences and inequalities set out in the presentation of the case study (diversity of origins, wealth, rootedness), circumstances that cannot easily be overcome. However, some firmly believe that conflict is not something to be eradicated but something to be dealt with:

... here we have to get on [well], there's a future to this. It is in the interests of the main families for business to prosper and not to kill the goose that lays the golden egg, which is tourism; and ultimately, we are a community, because we see each other every day. [ ... ] The current conflict is like a hobby, but deep down they all need one another, we need one another, even if we are mad at each other.

\section{Discussion}

On account of CBT, tourism has triggered collective reflection and action in Floreana. Tourism is not an influx to which the island must adapt; rather, a change in model has been implemented that entails controlling the growth of tourism, without sacrificing quality of life. However, its effect on socio-ecological resilience might be ambivalent.

The recent crisis caused by the COVID-19 pandemic is a good litmus test to examine its effect on the diversification of activities, a key element in the island's resilience. We have seen that CBT fosters diversification and that its role in the local economy cannot be understood without public sector jobs or dedication to farming activities on the upper part of the island. Since March 2020, the island has been closed to the outside world, and tourism has been suspended. The inhabitants of Floreana have continued to hold their public jobs and intensified their dedication to farming activities. They have made an example of their food sovereignty by not abandoning farming in spite of the rise in tourism, so that their geographical isolation does not make them completely dependent on the outside world to subsist. They are not receiving any revenues currently from tourism, but because they do not rely solely on this income their life on the island is not in danger. The model of tourism development by way of CBT puts them in an advantageous position when coping with this profound shock: their economy is viable without tourism, because they have not abandoned other activities. Some believe that this proves right those who argued to limit tourism and maintain above all a diversity of occupations, and very specifically food sovereignty, which is judged to be essential given the uncertainty surrounding the effects of the pandemic.

Community participation in tourism, however, might offer a less promising interpretation since its analysis casts doubt on the community's ability to overcome disagreements and dissent in the management of CBT, and, therefore, on the continuity of a model of socio-ecologically beneficial tourism. Having said that, collective tourism organisation was operating regularly and efficiently until the island was closed off due to the COVID-19 pandemic. Internal social fracture does not appear to have affected the collective capacity to maintain appropriate levels of tourist activity managed by CECFLOR. All of this has helped to bring down visitor numbers whilst maintaining revenues from tourism. Internal conflict exists, but it is dealt with, without preventing collective negotiations from continuing, just as some of the people involved have highlighted. However, it is reasonable to think that the structural conditions of diversity and inequality between tourism business owners will continue to be a source of conflict for the collective tourism business. Further research will be required in this regard in the future.

It will be precisely the capacity to nurture collective action around tourism that will guarantee the resilience of the socio-ecosystem in its current configuration. The islanders are empowered in their relationship with the state and the market, so that the sources made available to them by these two forces (public employment and flows of tourism) enable the islanders to develop the model of socio-ecosystem that interests them most. In contrast to the idea that external influences diminish 
the resilience of islands [37], Floreana goes against the current, insofar as the resources of the state and the market acquire community significance and meaning through a specific model of tourism development in the form of CBT.

However, this will not be possible unless the local community is able to deal with the internal conflict that is very easily triggered by the development of CBT, like a Pandora's box [38]. Floreana is at a crucial juncture, between the internal crisis provoked by the need to determine a model of sustainable tourism development and the limitations this imposes on business; and the external crisis caused by the COVID-19 pandemic: the suspension of tourism and the closure of the island. The resolution of this turning point will continue to inform research on whether CBT is a practice for long-term resilience in Floreana.

\section{Conclusions}

The aim of this article is further understanding of the effect of community-based tourism (CBT) on sustainability through resilience thinking. We proposed to develop a methodological perspective that focuses on two core elements in the functioning of any socio-ecosystem in which CBT is developed: (1) the diversification of productive activities; and (2) collective participation in tourism (controlling the tourist product and management, and collective decision-making). The case study analysed shows us that this strategy offers an appropriate means of explaining the effect and significance of CBT for the general resilience of the socio-ecosystem and, therefore, for the sustainability of its desired configuration. The analytical perspective proposed allows us to understand: (1) how CBT functions specifically in a given case, (2) its contribution to the resilience of the socio-ecosystem, and (3) the consistency of that resilience by virtue of the model of CBT developed.

CBT must make it possible, alongside the development of tourism, to broaden the community's reliance on different resources and, at the same time, to improve quality of life for the inhabitants. This analytical perspective complements other approaches that have focused on the effects of CBT in shaping the practices and attitudes of local populations $[9,10]$, broadening our gaze out towards the effect of CBT on the socio-ecosystem in general.

This way of analysing CBT, through its effect on resilience, helps us to understand the degree to which this model of tourism offers an alternative to conventional forms, in which the market is projected onto the community, imposing logics, criteria and developments that are not always desired locally and which erode the foundations of socio-economic sustainability.

However, our analytical proposal also has its limitations. Perhaps the most concerning one is the eminently contextual nature of its conclusions, a circumstance that is not only attributable to experiences of CBT but also to the analysis of resilience in general and its relationship with development $[7,39]$. It is not easy to draw general conclusions about the relationship between CBT and resilience, but one could aspire instead to design methodological strategies that would allow us to study each case from a longitudinal perspective in order to draw local conclusions. Nonetheless, we believe that this strategy allows us to examine meticulously each specific experience of CBT without any pre-established recipes or one-size-fits-all model, which are insufficient if we are seeking to understand the complexity of relationships between tourism and sustainability at a local level.

Author Contributions: Investigation, Formal analysis, Methodology and Writing, E.R.-B. and A.d.C.T.; Funding acquisition, Project administration and Writing-review \& editing, E.R.-B. All authors have read and agreed to the published version of the manuscript.

Funding: This work was supported by the Ministerio de Ciencia e Innovación (Spain) under grants CSO2017-84893-P (2018-2020) and CSO2012-33044 (2013-2016); and Charles Darwin Foundation/ Universidad Pablo de Olavide research project “Antropología de la Conservación en Galápagos” (2010-2013).

Conflicts of Interest: The authors declare no conflict of interest. 


\section{References}

1. Dangi, T.B.; Jamal, T. An Integrated Approach to Sustainable Community-Based Tourism. Sustainability 2016, 8, 475. [CrossRef]

2. Giampiccoli, A.; Saayman, M. Community-based tourism development model and community participation. Afr. J. Hosp. Tour. Leis. 2018, 7, 195059809.

3. Hiwasaki, L. Community-Based Tourism: A Pathway to Sustainability for Japan's Protected Areas. Soc. Nat. Resour. 2006, 19, 675-692. [CrossRef]

4. Okazaki, E. A Community-Based Tourism Model: Its Conception and Use. J. Sustain. Tour. 2008, 16, 511-529. [CrossRef]

5. Ruiz-Ballesteros, E. Keys for approaching community-based tourism. Gazeta de Antropología 2017, 33.

6. Ruiz Ballesteros, E.; Solis Carrión, D. (Eds.) Turismo comunitario en Ecuador. Desarrollo y Sostenibilidad Social; Abya-Yala: Quito, Ecuador, 2007.

7. Folke, C. Resilience (Republished). Ecol. Soc. 2016, 21, 44. [CrossRef]

8. Folke, C.; Carpenter, S.R.; Walker, B.; Scheffer, M.; Chapin, T.; Rockström, J. Resilience thinking: Integrating resilience, adaptability and transformability. Ecol. Soc. 2010, 15, 20. [CrossRef]

9. Ruiz-Ballesteros, E.; Ramos-Ballesteros, P. Social-Ecological Resilience as Practice: A Household Perspective from Agua Blanca (Ecuador). Sustainability 2019, 11, 5697. [CrossRef]

10. Ruiz-Ballesteros, E. Socio-ecological resilience and community-based tourism. An approach from Agua Blanca, Ecuador. Tour. Manag. 2011, 32, 655-666. [CrossRef]

11. Adger, W.N. Social and ecological resilience: Are they related? Prog. Hum. Geogr. 2000, 24, 347-364. [CrossRef]

12. Adger, N.; Hughes, T.; Folke, C.; Carpenter, S.; Rockström, J. Socio-ecological resilience to coastal disasters. Science 2005, 309, 1036-1039. [CrossRef]

13. Berkes, F.; Colding, J.; Folke, C. Navigating Socio-Ecological Systems; Cambridge University Press: Cambridge, UK, 2003.

14. Berkes, F.; Folke, C. (Eds.) Linking Social and Ecological Systems: Management Practices and Social Mechanisms for Building Resilience; Cambridge University Press: Cambridge, UK, 1998.

15. Berkes, F.; Seixas, C. Building resilience in Lagoon socio-ecological systems: A local-level perspective. Ecosystems 2005, 8, 967-974. [CrossRef]

16. Escalera Reyes, J. “Amor a la tierra”. Identidades colectivas y resiliencia de los socioecosistemas. In Complejidad y Ciencias Sociales; Ruiz-Ballesteros, E., Solana Ruiz, J.L., Eds.; UNIA: Sevilla, Spain, 2013; pp. 333-376.

17. Folke, C. Socio-ecological resilience and behavioural responses. In Individual and Structural Determinants of Environmental Practice; Biel, A., Hansson, B., Mårtensson, M., Eds.; Ashgate Publishers: London, UK, 2003; pp. 226-287.

18. Folke, C.; Carpenter, S.; Elmquist, T.; Gunderson, L.; Holling, S.; Walker, B. Resilience and sustainable development: Building adaptative capacity in a world of transformations. Ambio 2002, 312, 437-440. [CrossRef]

19. Walker, B.; Gunderson, L.; Kinzig, A.; Folke, C.; Carpenter, S.; Schultz, L. A handful of heuristics and some propositions for understanding resilience in socio-ecological systems. Ecol. Soc. 2006, 11, 13-27. [CrossRef]

20. Biggs, R.; Schlüter, M.; Biggs, D.; Bohensky, E.L.; BurnSilver, S.; Cundill, G.; Dakos, V.; Daw, T.M.; Evans, L.S.; Kotschy, K.; et al. Toward Principles for Enhancing the Resilience of Ecosystem Services. Annu. Rev. Environ. Resour. 2012, 37, 421-448. [CrossRef]

21. Carpenter, S.R.; Arrow, K.J.; Barrett, S.; Biggs, R.; Brock, W.A.; Crépin, A.-S.; Engström, G.; Folke, C.; Hughes, T.P.; Kautsky, N. General Resilience to Cope with Extreme Events. Sustainability 2012, 4, 3248-3259. [CrossRef]

22. De Certeau, M. The Practice of Everyday Life; University of California Press: Berkeley, CA, USA, 1984.

23. Armitage, D.; Berkes, F.; Doubleday, N. Introduction: Moving beyond co- management. In Adaptive Co-Management. Collaborations, Learning and Multi-Level Governance; Armitage, D.F., Berkes, F., Doubleday, N., Eds.; University of British Columbia Press: Vancouver, BC, Canada, 2007; pp. 1-18.

24. Zwiers, S.; Markantoni, M.; Strijker, D. The role of change- and stability-oriented place attachment in rural community resilience: A case study in south-west Scotland. Community Dev. J. 2016, 53, 281-300. [CrossRef] 
25. Stylidis, D. Place attachment, perception of place and residents' support for tourism development. Tour. Plan. Dev. 2018, 15, 188-210. [CrossRef]

26. Patwardhan, V.; Ribeiro, M.A.; Payini, V.; Woosnam, K.M.; Mallya, J.; Gopalakrishnan, P. Visitors' Place Attachment and Destination Loyalty: Examining the Roles of Emotional Solidarity and Perceived Safety. J. Travel Res. 2020, 59, 3-21. [CrossRef]

27. Del Campo Tejedor, A. Autoridad y liderazgo en Huertas (Shaglli). Prácticas y tácticas de articulación entre sujeto, comunidad y mundo. In Turismo Comunitario en Ecuador, Desarrollo y Sostenibilidad Social; Ruiz-Ballesteros, E., Solis Carrión, D., Eds.; Abya-Yala: Quito, Spain, 2007; pp. 219-275.

28. Ruiz-Ballesteros, E. Agua Blanca. Comunidad y Turismo en El Pacífico Ecuatorial; Abya-yala: Quito, Spain, 2009.

29. Parque Nacional Galápagos. Informe Visitantes a Las Áreas Protegidas de Galápagos 2019. Available online: http://www.galapagos.gob.ec/wp-content/uploads/2020/01/INFORME-ANUAL-DEVISITANTES-2019.pdf (accessed on 20 April 2020).

30. Andrada, J.; Cantero, P.; Ruiz-Ballesteros, E. Floreana, Islamundo en Galápagos; Abya-Yala: Quito, Spain, 2015.

31. Ruiz-Ballesteros, E. Comunidad, bienes comunes y turismo en Floreana (Islas Galápagos). Revista de Antropología Social 2017, 26, 333-354. [CrossRef]

32. Ewel, J.; Mascaro, J.; Kueffer, C.; Lugo, A.E.; Lach, L.; Gardener, M.R. Islands: Where Novelty is the Norm. In Novel Ecosystems. Intervening in the New Ecological World Order; Hobbs, R.J., Higgs, E.S., Hall, C.M., Eds.; Wiley-Blackwell: Hoboken, NJ, USA, 2013.

33. Ruiz-Ballesteros, E.; Brondizio, E.S. Building negotiated agreement: The emergence of community based tourism in Floreana (Galapagos Islands). Hum. Organ. 2013, 72, 323-335. [CrossRef]

34. Charmaz, K. Qualitative interviewing and grounded theory analysis. In Inside Interviewing: New Lenses, New Concerns; Holstein, J.A., Gubrium, J.F., Eds.; Sage: London, UK, 2003; pp. 311-330.

35. Glaser, B.G.; Strauss, A.L. The Discovery of Grounded Theory: Strategies for Qualitative Research; Weidenfeld and Nicolson: London, UK, 1967.

36. Observatorio Turismo de Galápagos, Estadísticas Turismo Galápagos 2018. Available online: http://www. galapagos.gob.ec/estadistica-de-visitantes/ (accessed on 25 May 2019).

37. Campbell., J. Islandness: Vulnerability and Resilience in Oceania. Shima Int. J. Res. Isl. Cult. 2009, 3, 85-97.

38. Simons, I.; de Groot, E. Power and empowerment in community based tourism:Opening Pandora's box? Tour. Rev. 2015, 70, 72-84. [CrossRef]

39. Brown, K. Resilience, Development and Global Change; Routledge: London, UK, 2016. 